\title{
IDENTIFICAÇÃO DAS FEIÇÕES ESPECTRAIS DA CAULINITA E DA GIBSITA DE \\ UM LATOSSOLO VERMELHO-AMARELO DO MUNICÍPIO DE MORRO DO \\ CHAPÉU-BA
}

\author{
$\underline{\text { Roneíse de Jesus Lima }}{ }^{1}$; Joselisa Chaves ${ }^{2}$;Deorgia Tayane Mendes de Souza $^{3}$ e \\ Washington Franca-Rocha ${ }^{4}$ \\ 1. Bolsista PIBIC/CNPq, Graduando em Geografia, Universidade Estadual de Feira de Santana, e-mail: \\ isedelima@gmail.com \\ 2. Orientador, Departamento de Ciências Exatas, Universidade Estadual de Feira de Santana, e-mail: \\ josimariachaves@gmail.com \\ 3. Coorientador, Departamento de Ciências Humanas e Filosofia, Universidade Estadual de Feira de Santana, e-mail: \\ deorgiasouza.geo@gmail.com \\ 4. Coorientador, Departamento de Ciências Exatas, Universidade Estadual de Feira de Santana, e-mail: \\ francarocha@gmail.com
}

PALAVRAS-CHAVE: argilominerais; sensoriamento remoto; pedologia.

\section{INTRODUÇÃO}

A análise espectral é uma técnica de definição da composição química da substancia através do seu espectro, tendo como função, segundo Pedrosa (2010), medir em diferentes comprimentos de onda a energia eletromagnética refletida da superfície dos materiais e representá-la na forma de um gráfico que se denomina de curva de reflectância espectral, onde é possível identificar o comportamento espectral desses materiais.

Para tanto, uma das formas de analisar o comportamento espectral das amostras de solo é fazendo uma divisão espectral em segmentos, definindo, assim, a curva em tais segmentos. Neste caso são analisadas as características dos solos destacando seus constituintes, afirmam Epiphanio et al. (1992).

Para auxiliar na avaliação do comportamento espectral dos solos são normalmente empregados métodos no processamento dos dados espectrorradiométricos, tais a técnica de remoção do espectro contínuo (TERRA, 2011). Que, segundo Breuning et al. (2007), foi proposta por Clark e Rough (1984), e consiste na remoção das feições contínuas dos espectros, onde o contínuo é uma função matemática utilizada para isolar bandas de absorção particulares dos espectros de reflectância, o que permiti qualificar a análise espectral.

Assim, medem-se os espectros de minerais, cujas bandas de absorção ocorrem no intervalo do Visível ao Infravermelho Próximo (SWIR), como a caulinita e a gibsita, são originadas basicamente das transições eletrônicas de transferência de carga e de campo cristalino, envolve a movimentação de elétrons dentro da matéria, algo que ocorre frequentemente ao longo de uma molécula ou através de um sólido e atração entre cargas, respectivamente.

Ancorando-se nas teorias - sobre sensoriamento remoto, espectrorradiometria, comportamento espectral e solos - fundamentos e técnicas acima apresentadas, este trabalho tem como objetivo central foi identificar as feições espectrais da caulinita e da gibbisita de um Latossolo Vermelho-amarelo.

\section{METODOLOGIA}

Morro do Chapéu (figura 1), área de estudo da presente pesquisa, é um município do estado da Bahia localiza-se na região da Chapada Diamantina, na porção central do estado. Com predominância do clima tropical, fortemente alterado pela 
altitude variando ente 480 a $1.293 \mathrm{~m}$, relevo caracterizado por formas tabulares, com grande diversificação geológica e da vegetação (CPRM, 1995).

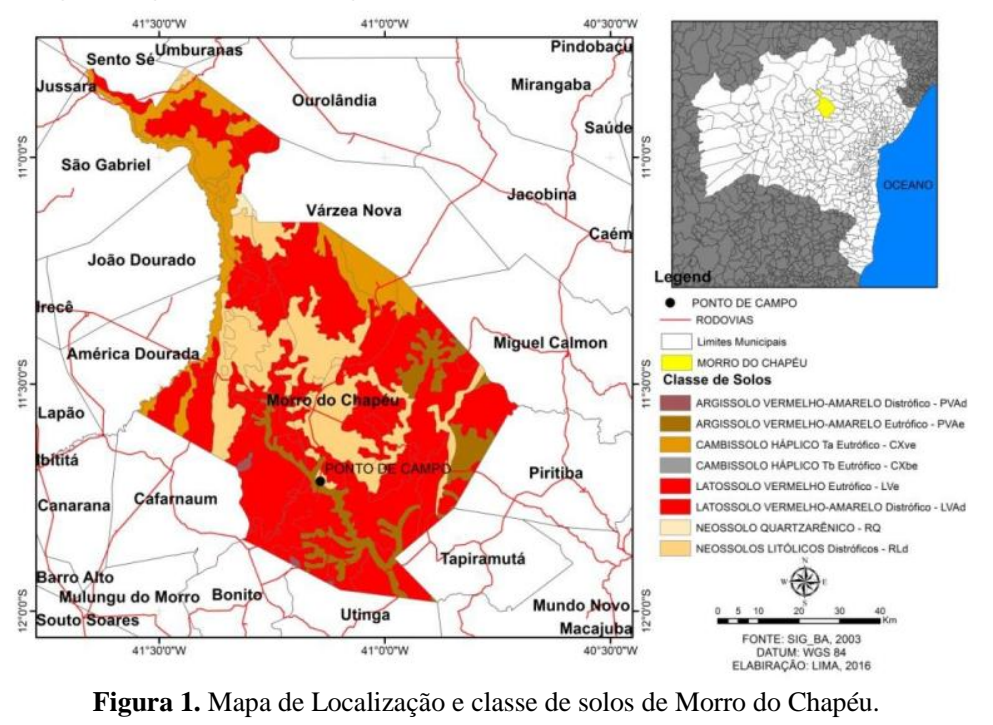

Para tanto, foram efetivados as seguintes etapas metodológicas: (1) Levantamento bibliográfico: por meio de livros, artigos e teses como suporte teórico para um melhor desenvolvimento da pesquisa, com base em estudos sobre espectrorradiômetria para o estudo de solos, mineralogia e solos; (2) Pesquisa de campo: que teve como finalidade a definição de horizontes e coleta de amostras de solos, tendo como base o Sistema Brasileiro de Classificação de Solos (EMBRAPA, 2006); (3) Análise laboratorial do solo: baseada na metodologia de Ben-Dor (1997), utilizando o Espectrorradiômetros ASD FieldSpec, realizada no Laboratório de Espectrorradiometria do Programa de Pós-Graduação em Ciências da Terra e do Ambiente da UEFS. As amostras de solo coletadas em campo foram, destorroadas e peneiradas com espessura de $2 \mathrm{~mm}$ secas a $45^{\circ} \mathrm{C}$ por $24 \mathrm{~h}$; (4) Análise das curvas espectrais e da técnica utilizada: que foram elaboradas no software ENVI, e aplicação da remoção do continuo;

\section{RESULTADOS E DISCUSSÃO}

O solo amostrado para analises espectrais é da classe de solos Latossolo Vermelho-amarelo. Foram identificados três horizontes: Horizonte A, Horizonte Bl e Horizonte $\mathrm{Bx}$ ( $\mathrm{x}=$ cimentado).

Foram encontradas no perfil analisado No intervalo do SWIR, as bandas de absorção $1.4 \mu \mathrm{m}$, são referentes à caulinita (BAPTISTA, 2006), e foram identificados nos horizontes A, Bl e Bx. As bandas de absorção $1.9 \mu \mathrm{m}$, indica presença de água molecular absorvida (BAPTISTA, 2006), ou seja, presença de moléculas de hidroxila $(\mathrm{OH})$ e de água na estrutura de minerais, identificados em todos os horizontes.

Bandas de absorção $2,2 \mu \mathrm{m}$, indica intensificação da feição de caulinita (BAPTISTA, 2006), identificados nos horizontes A, Bl e Bx. As bandas de absorção 2.3 $\mu \mathrm{m}$, são referente a gibbsita (BAPTISTA, 2006), e foram identificados nos horizontes $\mathrm{A}, \mathrm{Bl}$ e Bx. 

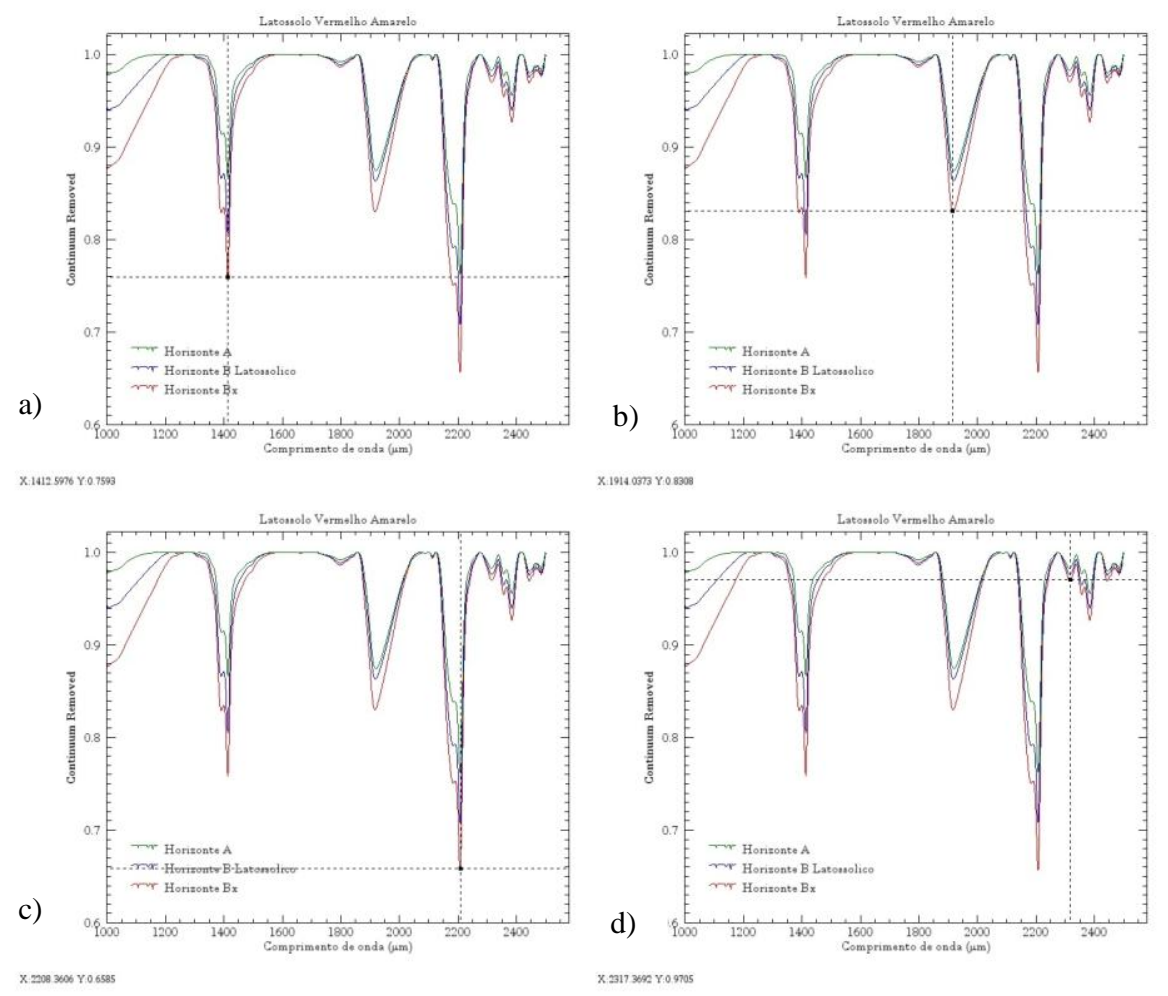

Figura 2. Curvas espectrais do Latossolo Vermelho-amarelo identificando os argilominerais caulinita e gibbsita. a)

Banda de absorção $1.4 \mu \mathrm{m}$; b) Banda de absorção $1.9 \mu \mathrm{m}$; c) Banda de absorção $2.2 \mu \mathrm{m}$; d) Banda de absorção 2.3

$\mu \mathrm{m}$.

As principais feições espectrais da caulinita são devidas as vibrações das hidroxilas (OH-) de sua rede cristalina. As absorções fundamentais situam-se no infravermelho médio onde cada uma das quatro $\mathrm{OH}$ - determinam uma absorção no infravermelho próximo e médio as absorções perceptíveis. (EPIPHANIO, et al. 1992).

A caulinita tende a se ajustar, face a face, aumentando o grau de coesão entre as partículas do solo. Já a gibbsita é responsável pela formação de estruturas granulares, e decorrentes disso a formação de macroporos que, ou seja, é decorrente dessa estrutura em macroporos que evidencias características físicas dos Latossolos, como a resistente à erosão e a capacidade de retenção de água (RESENDE et al., 2007).

Assim, solos que foram sujeitos à alteração, como é o caso da classe de solo analisada, apresentam significativos teores de gibbsita na sua composição, sendo este um óxido de alumínio hidratado, é também, é formada em intemperismo tropical de rochas com silicato de alumínio, a firma Baptista (2006).

Para tanto, a importância de argilominerais no solo, como a caulinita, se dá, decorrente de sua característica e significativa contribuição às propriedades físicas e químicas do solo. E sua alta frequência nos solos, deve-se, na maioria das vezes, a possibilidade de sua formação a partir de muitos minerais diferentes, ocorrendo remoção parcial de cátions básicos e de sílica, afirmam Ker et al. (2012).

Assim, os Latossolos, caracterizados como solos caulííticos (KER et al., 2012), são solos com baixa reserva em nutrientes, podem apresentar resíduos do seu mineral fonte, maior estabilidadefísica e menor erodibilidade, já que não apresentam capacidade de expansão e de concentração com a variação do grau de umidade no solo, além de menor dispersibilidade em água. Além do mais, a caulinita, em Latossolos, está associada a estruturas em blocos e confere a possibilidade de retenção de ânions em pH ácido e de cátions em $\mathrm{pH}$ elevado.

Para Ker et al. (2012), essas caulinitas ajudam a compreender a gênese do caráter coeso, implicando menor infiltração de água no perfil, além de grande 
dificuldade de penetração do sistema radicular das plantas nos meses mais secos, aspecto este revertido quando o solo está úmido.

Já referente à presença da gibbsita, Ker et al. (2012) afirma que quando em maiores concentrações, como nos Latossolos, dificultam o ajuste face a face das placas de caulinita, facilitando a estrutura granular muito pequena, ocasionando maior infiltração de água, maior porosidade e menor densidade do solo, excedendo, assim, o efeito da textura no comportamento físico desse solo.

\section{CONSIDERAÇÕES FINAIS}

Através das técnicas de remoção do contínuo é possível identificar os identificar feições da caulinita nos comprimentos de onde $1.4 \mu \mathrm{m}$ e $2.2 \mu \mathrm{m}$, e gibbsita no comprimento de onda $2.3 \mu \mathrm{m}$ no perfil analisado. Auxiliando, assim, de forma mais precisa nas analises de campo, amparando, também, instrumento que dinamiza a análise conservação e manejo do solo.

\section{REFERÊNCIAS}

BAPTISTA, G. M. M.;CORRÊA, R. S.; TORRES, M. G.; BIAS, E. S.; RESENDE, M. G.; RIBEIRO, R. J. C.; SILVA, D. J. Identificação de relação mineral Caulinita/Gibbsita em solos tropicais, por meio dosdados SWIR do sensor ASTER. Anais XIII Simpósio Brasileiro de Sensoriamento Remoto, Florianópolis, Brasil, 21-26 abril 2007, INPE, p. 7043-7050.

BEN-DOR, E. et al. The reflectance spectra of organic matter in the visible nearinfrared and short wave infrared region (400-2500) during a controlled decomposition process. Remote Sensing of Environment, New York, v.61, p.1-15, 1997.

CAMPOS, P. M; LACERDA, M. P. C; PAPA, R. A.; GUIMARÃES, E. M.; COSTA NETO, F. Difratômetria de raios X aplicada na identificação de gibsita e caulinita em latos solos do Distrito Federal. In: SIMPÓSIO NACIONAL CERRADO, 9., SIMPÓSIO INTERNACIONAL SAVANAS TROPICAIS 2., 2008, Brasília. Anais... Brasília, 2008. p. 01-07.

CPRM - Serviços Geologicos do Brasil. Projeto Mapas Municipais - Município de Morro do Chapéu (Ba) : informações básicas para o planejamento e administração do meio físico/Organizado por Antônio José Dourado Rocha e Ivanaldo Vieira Gomes da Costa. - Salvador : CPRM, 1995. 3 v.: il. color. ; 16 mapas anexo, gráficos, tabelas. EPIPHANIO, J.C.N.; FORMAGGIO, A.R.; VALERIANO, M.M.; OLIVEIRA; J.B. Comportamento espectral de solos do Estado de São Paulo. São José dos Campos, SP, INPE, 1992. 132 p. (INPE-5424-PRP/172).KER, J. C.; CURI, N.; SCHAEFER, C.E.G.R.; TORRADO, P. V. Pedologia: fundamentos. / Editores João Carlos Ker [et al.]. - Viçosa, MG: SBCS, 2012. 343p. : il. (algumas col.) ; $26 \mathrm{~cm}$.

LEPSCH, I. F. Formação e conservação dos solos / Igo F. Lepsch. 2. ed. - São Paulo: Oficina de Texto, 2010.

PEDROSA, S. A.; MENESES, P. R.; CARMELO, A. C. Espectrorradiometria de reflectância de rochas carbonáticas na região do infravermelho de ondas curtas. Revista Brasileira de Geociências Sandra Aparecida Pedrosa et al.. 40(4): 593-599, dezembro de 2010 Arquivo digital disponível on-line no site www.sbgeo.org.br 593.

RESENDE, M.; CURI, N.; RESENDE, S. B. de; CORREAA, G. F. Pedologia: base para distinção de ambientes. $5^{\text {a }}$ ed. Lavras: Editora UFLA, 2007. 332 p.:il.

TERRA, F. S. Espectroscopia de reflectância do visível ao infravermelho médio aplicada aos estudos qualitativos e quantitativos de solos. Tese de doutorado. 2011. 375 f. Esalq, Piracicaba, SP. 